\title{
Aspect sensitivity of polar mesosphere summer echoes based on ESRAD MST radar measurements in Kiruna, Sweden in 1997-2010
}

\author{
M. Smirnova, E. Belova, and S. Kirkwood \\ Swedish Institute of Space Physics, Kiruna, Sweden \\ Correspondence to: E. Belova (belova@irf.se)
}

Received: 13 September 2011 - Revised: 12 January 2012 - Accepted: 21 February 2012 - Published: 1 March 2012

\begin{abstract}
Aspect sensitivities of polar mesosphere summer echoes (PMSE) measured with the ESRAD $50 \mathrm{MHz}$ radar in 1997-2010 are studied using the full correlation analysis technique. Half of PMSE detected each year are found to be highly aspect sensitive. Yearly median values of the aspect sensitivity parameter $\theta_{\mathrm{s}}$, characterising the half-width of the scatterers' polar diagram, are $2.9-3.7^{\circ}$ depending on the year. The other half of the PMSE have $\theta_{\mathrm{S}}$ values larger than $9-11^{\circ}$ and cannot be evaluated using the ESRAD vertical beam only. PMSE aspect sensitivity reveals an altitude dependence, namely, the scatter becomes more isotropic with increasing height. This result is consistent with that reported in other studies. No dependence of PMSE aspect sensitivity on backscattered power for any year was identified. In the paper the limitations of the in-beam and off-vertical beam methods for estimation of PMSE aspect sensitivity are discussed. We conclude that both methods should be combined in order to get complete information about PMSE aspect sensitivity and to estimate correctly PMSE absolute strength.
\end{abstract}

Keywords. Meteorology and atmospheric dynamics (Middle atmosphere dynamics)

\section{Introduction}

Polar Mesosphere Summer Echoes (PMSE) are extremely strong radar echoes observed from altitudes of $80-95 \mathrm{~km}$ at high latitudes in the Northern and Southern Hemispheres during summer. Nowadays, it is known that PMSE occur due to scattering from fluctuations in electron density caused by atmospheric turbulence in the presence of ice particles formed from water vapour due to the low temperatures $(\sim 130 \mathrm{~K})$ at the summer mesopause. Since PMSE are closely related to temperature changes and may follow climate change (e.g. Thomas and Olivero, 2001), they have attracted considerable interest from the scientific community during the last three decades. A review of PMSE investigations can be found in Rapp and Lübken (2004).

Despite long and intensive studies of PMSE, their aspect sensitivity is still an intriguing and open question. Aspect sensitivity is a property of the scatterers which describes the variation of scattered power in respect of incident angle. It is quantified in terms of the half width $\theta_{\mathrm{S}}$ of the angular polar diagram of backscatter (Hocking et al., 1986). Isotropic scatterers are non-aspect sensitive and have broad polar diagram, and anisotropic, specular ones are highly aspect sensitive, i.e. have a narrow backscatter beam. The early measurements of aspect sensitivity of PMSE by Czechowsky et al. (1988) showed that PMSE are highly aspect sensitive with typical $\theta_{\mathrm{s}}$ of $5^{\circ}-6^{\circ}$ at altitudes of $85-86 \mathrm{~km}$. Further works on this subject reported a variety of values of $\theta_{\mathrm{S}}$ in this altitude range: e.g. $12^{\circ}-13^{\circ}$ (Huaman and Balsley, 1998), 3.5 and $7^{\circ}-10^{\circ}$ (Zecha et al., 2001), $11^{\circ}-15^{\circ}$ (Swarnalingam et al., 2011). This implies that PMSE can be specular (or due to anisotropic turbulence) as well as rather isotropic.

Why is aspect sensitivity interesting for PMSE researchers? Firstly, as we shortly discussed above, aspect sensitivity measurements can provide some idea about scattering processes and the scatterers themselves. Swarnalingam et al. (2011) gave a short overview of main models of coherent scatter for VHF radars. Not all radar observations in the middle atmosphere were consistent with the two classical extreme models: turbulent volume isotropic scatter and specular Fresnel reflection. Therefore new models for anisotropic turbulence and Fresnel scatter were suggested (for references see Swarnalingam et al., 2011).

There is another important effect of PMSE aspect sensitivity which has not received proper attention yet. Knowledge of aspect sensitivity could be essential for correct estimation of absolute strength of PMSE. For instance, highly aspect sensitive echoes might not fill a whole radar sampling volume. Then with the usual assumptions of the volume (isotropic) scatter of $100 \%$ filling, one could underestimate 
Table 1. ESRAD operating parameters/modes used in this study.

\begin{tabular}{lll}
\hline Radar parameter/mode & $\begin{array}{l}\text { fca_150 for } \\
1997-2002\end{array}$ & $\begin{array}{l}\text { fca_150 for } \\
2003-2010\end{array}$ \\
\hline Transmitter peak power & $72 \mathrm{~kW}$ & $72 \mathrm{~kW}$ \\
$\mathrm{e}^{-1}$ half-beam width & $3.98^{\circ}$ & $2.65^{\circ}$ \\
Pulse length $(3 \mathrm{~dB})$ & $1 \mu \mathrm{s}$ & $1 \mu \mathrm{s}$ \\
Altitude resolution & $150 \mathrm{~m}$ & $150 \mathrm{~m}$ \\
Code & $8 / 16-$ bit complementary & none \\
Coherent integrations & $64 / 128$ & 256 \\
Pulse repetition frequency & $1450 \mathrm{~Hz}$ & $4688 \mathrm{~Hz}$ \\
\hline
\end{tabular}

the actual volume reflectivity of PMSE. Another possible application area for the aspect sensitivity measurements is in inter-comparisons of PMSE observed with different radars. These studies, including PMSE interhemispheric and latitudinal differences, became very popular in the last several years (Kirkwood et al., 2007; Latteck et al., 2008; Morris et al., 2009; Swarnalingam et al., 2009b). However, because the radars involved in these studies have various antennas with different beam-width and PMSE at the radar locations might have different aspect characteristics, corrections should be made in the calculations of PMSE strength. Moreover, isotropic (turbulent) and Fresnel scattering mechanisms lead to very different cross-sections (e.g. Kirkwood et al., 2010). Therefore in the cases of isotropic and aspectsensitive PMSE, estimation of their cross-sections using observations requires quite different calculations to account for radar characteristics (for a given echo power at the radar receiver, volume reflectivity of isotropic scattering depends on the antenna effective area, whereas Fresnel reflectivity depends on the square of that area).

Aspect sensitivities have been obtained from radar measurements by two different methods: (1) by comparing the echo strengths from vertical and off-vertical radar beams or in another terminology, Doppler beam swinging, DBS, (2) by in-beam estimates using spaced antennas (SA). The latter applies coherent radar image (CRI) or the full correlation analysis (FCA) techniques. Hobbs et al. (2001) described both methods and their limitations resulting from the theoretical assumptions and experimental configurations. Chilson et al. (2002) pointed out that in an application to the mesosphere a disadvantage of the DBS method is in the long distance between the radar sampling volumes because large off-zenith angles are used. We will discuss more limitations for both methods later in this paper.

In the majority of PMSE aspect sensitivity studies the DBS method was used (Czechowsky et al., 1988; Hoppe et al., 1990; Huaman and Balsley, 1998; Swarnalingam et al., 2011, and others). Chilson et al. (2002) applied CRI technique to PMSE and related the angular brightness distribution to aspect sensitivity. Zecha et al. (2001) used both DBS and FCA methods in the same PMSE experiment using the ALOMAR SOUSY VHF radar. They found that the DBS method yields higher values of $\theta_{\mathrm{s}}$ for the same PMSE layer than the SA method. (This should be borne in mind for the results presented in Sect. 4.) The authors argued that these two methods evaluate aspect sensitivity at different spatial scales and PMSE is strongly anisotropic within a radar beam but more isotropic on larger distances. We suggest another possible interpretation of the discrepancy in the results obtained with DBS and SA methods in the Discussion section. There are also several papers dealing with indirect estimation of aspect sensitivity of the mesospheric summer echoes, e.g. via the relationship between the echo power and its spectral width (e.g. Chen et al., 2004). However, we will not touch on those results in this paper where we concentrate on quantitative characterisation of aspect sensitivity, i.e. on calculation of $\theta_{\mathrm{s}}$.

Here we present the results of PMSE aspect sensitivity measurements over the period 1997-2010 using the ESRAD MST radar located near Kiruna in Northern Sweden. We have used the FCA technique which provides us with inbeam estimates of aspect angle $\theta_{\mathrm{s}}$. We discuss a limitation of this technique in application to the ESRAD radar. We analyze the dependence of aspect sensitivity on PMSE height as well as on backscattered power and compare our results with those of others. Finally, we evaluate the effect of PMSE aspect sensitivity on estimation of their volume reflectivity.

\section{Experiment description}

PMSE measurements have been carried out with the ESRAD $52 \mathrm{MHz}$ radar, situated at the rocket range Esrange, Sweden $\left(67.88^{\circ} \mathrm{N}, 21.10^{\circ} \mathrm{E}\right)$ during the years $1997-2010$, although observations from 1999 are not considered here due to a radar malfunction. ESRAD provides information on the dynamic state of the lower and middle atmosphere such as winds, waves, turbulence and layering. A detailed description for ESRAD was given by Chilson et al. (1999) and updated by Kirkwood et al. (2007).

For PMSE measurements ESRAD was operated in different modes with the radar beam pointed vertically. In this paper we consider the data with the highest available altitude resolution of $150 \mathrm{~m}$. The measurements collected in 2002 and 2004 are not included since, during these years, ESRAD was operated in modes providing only $300 \mathrm{~m}$ or $600 \mathrm{~m}$ altitude resolutions. Initially the $\mathrm{e}^{-1}$ half-width of the radar transmit beam was $3.98^{\circ}$, then in 2004 the antenna array was extended which made this radar beam width narrower, at $2.65^{\circ}$. The details of the radar measurement set-up are presented in Table 1.

ESRAD was operated in 6-receiver mode which allows the implementation of FCA analysis. The FCA technique was developed by Briggs (1985). The principle behind this technique is the following: the scatterers lead to a diffraction pattern on the ground, which moves across the antenna array, as the scatterers drift horizontally. By using several (at least three) non-colinear antenna sub-arrays for reception 
and calculating cross-correlations between them, under certain assumptions one can derive spatial parameters of the diffraction pattern. Finally, from them the aspect sensitivity is estimated. We consider the calculation of aspect sensitivity in more detail in the next section.

\section{Calculation of aspect sensitivity}

A radar transmits radiation in a certain beam pattern, which can be expressed by a polar diagram. When radiation reaches scatterers they reradiate back with a polar diagram of backscatter defined by their aspect sensitivity. This backscatter is received by the radar in accordance of its receive beam which can differ from the transmit one (as it does for the FCA technique). The backscatter pattern that we receive back at the radar can be described by an effective polar diagram. We follow Hocking et al. (1986) and approximate every polar diagram by the expression

$P(\theta)=\exp \left[-\frac{\sin ^{2} \theta}{\sin ^{2} \theta_{0}}\right]$,

where $\theta$ is the zenith angle and $\theta_{0}$ is $\mathrm{e}^{-1}$ half-width of the polar diagram. Then the effective polar diagram is the product of polar diagrams of transmit and receive beams and that of the scatterers, i.e.

$$
\begin{aligned}
P_{\text {eff }}(\theta) & =\exp \left[-\frac{\sin ^{2} \theta}{\sin ^{2} \theta_{\text {eff }}}\right] \\
& =\exp \left[-\frac{\sin ^{2} \theta}{\sin ^{2} \theta_{T}}-\frac{\sin ^{2} \theta}{\sin ^{2} \theta_{R}}-\frac{\sin ^{2} \theta}{\sin ^{2} \theta_{\mathrm{s}}}\right],
\end{aligned}
$$

where $\theta_{\text {eff }}$ is the $\mathrm{e}^{-1}$ half-width of the effective polar diagram, $\theta_{\mathrm{T}}$ is the $\mathrm{e}^{-1}$ half-width of the radar transmit beam, $\theta_{\mathrm{R}}$ is the $\mathrm{e}^{-1}$ half-width of the radar received beam, $\theta_{\mathrm{s}}$ is the $\mathrm{e}^{-1}$ half-width of the scatter polar diagram of the scatterers. $\theta_{\mathrm{s}}$ is a measure of aspect sensitivity, or in the same terminology as e.g. in Swarnalingam et al. (2011) is the aspect sensitivity parameter.

We made use of FCA results for the calculation of $\theta_{\text {eff }}$ as described by e.g. Holdsworth (1995):

$\theta_{\text {eff }}=\frac{15.2 \lambda \sqrt{R_{\mathrm{ax}}}}{S_{0.5}}$

where $\lambda$ is the radar wavelength, $R_{\mathrm{ax}}$ and $S_{0.5}$ are the axis ratio and scale of the diffraction pattern, respectively, estimated by the FCA technique.

Finally, for given $\theta_{\mathrm{T}}$ and $\theta_{\mathrm{R}}$ the aspect sensitivity parameter $\theta_{\mathrm{S}}$ can be found from the equation:

$\sin ^{-2} \theta_{\mathrm{s}}=\sin ^{-2} \theta_{\mathrm{eff}}-\left(\sin ^{-2} \theta_{\mathrm{T}}+\sin ^{-2} \theta_{\mathrm{R}}\right)$

Finite transmit and receive radar beam widths set limits for in-beam measurements of aspect sensitivity. If, for instance,

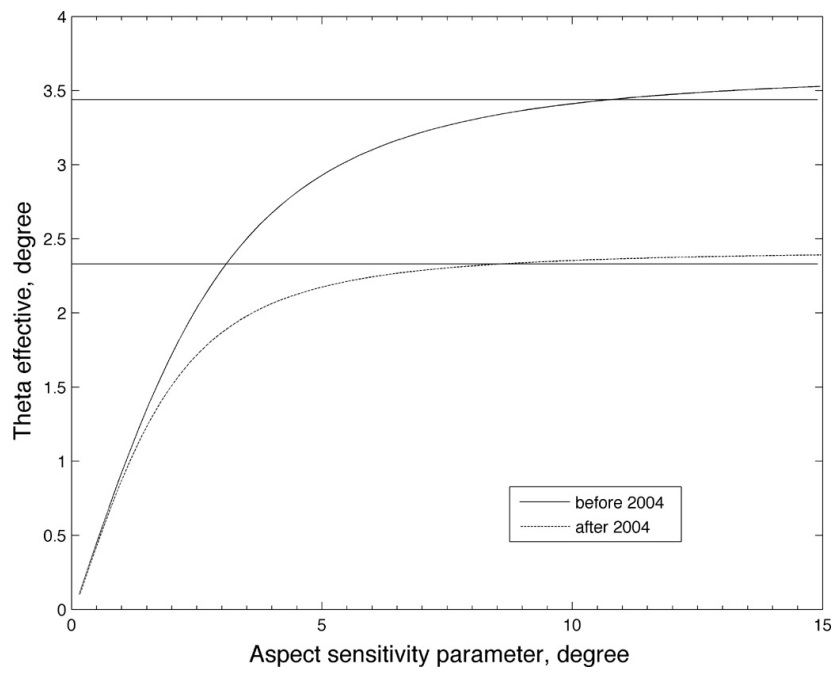

Fig. 1. The $\mathrm{e}^{-1}$ half-width $\theta_{\text {eff }}$ of the effective polar diagram of received signal as a function of aspect sensitivity parameter $\theta_{\mathrm{S}}$ (= the $\mathrm{e}^{-1}$ half-width of the scatter polar diagram of the scatterers) for two radar half-beam widths: $3.98^{\circ}$ before 2004 and $2.65^{\circ}$ after 2004 .

a radar beam is narrow, one cannot distinguish between two types of scatterers whose backscatter beam widths (i.e. aspect sensitivity) are larger than that of the radar. In order to study this in application to ESRAD we computed $\theta_{\text {eff }}$ using Eq. (4) for various values of aspect sensitivity for the actual ESRAD transmitted beam width. 6 rectangular antenna subarrays were used for reception (each $6 \times 8$ Yagi antennas, $4 \times 6$ before 2004), with mean beam width $\theta_{\mathrm{R}}$ of $6^{\circ}$ $\left(9^{\circ}\right.$ before 2004) as described in more detail by Kirkwood et al. (2010). In Fig. 1, the effective polar diagram width $\theta_{\text {eff }}$ as a function of aspect sensitivity parameter $\theta_{\mathrm{s}}$ is presented. From this figure we see that $\theta_{\text {eff }}$ strongly depends on $\theta_{\mathrm{s}}$ only for the interval from $0^{\circ}$ up to about $3.4^{\circ}\left(2.3^{\circ}\right.$ after 2004). By the other words, the measurable quantity $\theta_{\text {eff }}$ is sensitive to scatterers' aspect sensitivity $\theta_{\mathrm{S}}$ only when $\theta_{\mathrm{eff}}<3.4^{\circ}\left(2.3^{\circ}\right.$ after 2004). In application to the real experimental data, containing both signal and noise, this implies the following. For two measured values of $\theta_{\text {eff }}>3.4^{\circ}$ (before 2004) where signal amplitudes are close to each other (i.e. from the same sort of scatterer) but noise was imperfectly removed, by using Eq. (4) one can get not only very different, but unreasonably large values of aspect sensitivity parameter $\theta_{\mathrm{s}}$. Figure 1 gives us maximum values of $\theta_{\text {eff }}$ which can be used for accurate derivation of aspect sensitivity from the ESRAD data corresponding to maximum $\theta_{\mathrm{S}}$ of about $11^{\circ}\left(9^{\circ}\right.$ after 2004) which we are able to detect using the ESRAD vertical beam. 

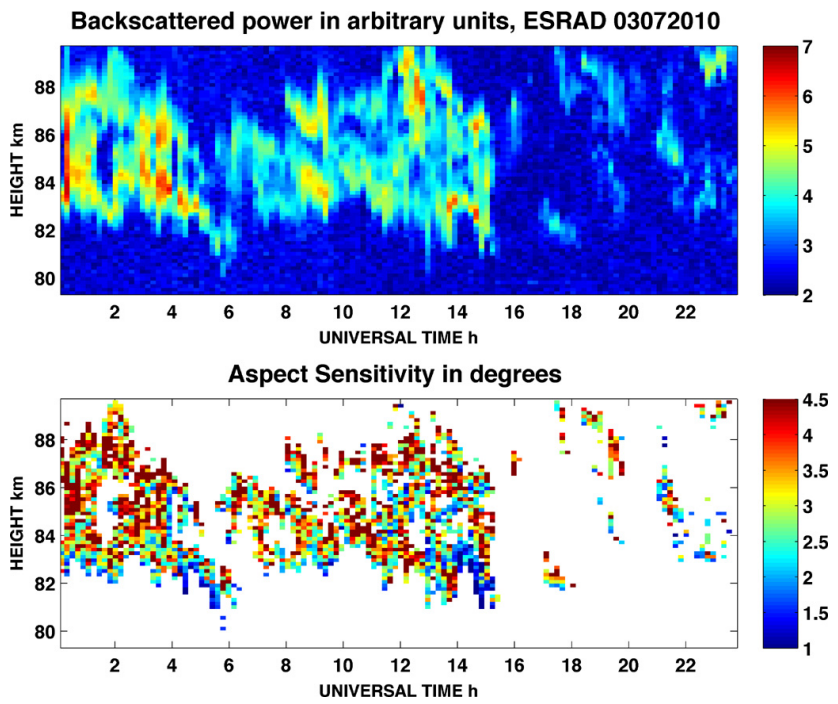

Fig. 2. Backscattered power (the upper panel) and aspect sensitivity (the lower panel) measured with ESRAD MST radar on 3 July 2010.

\section{Results}

\subsection{Aspect sensitivity of PMSE}

Firstly, we computed $\theta_{\text {eff }}$ using FCA analysed data for the altitude range 80-90 km for the interval from 1 June to 31 July for each year. FCA is applied only for echoes with signalto-noise ratio more than 1 . Then by applying the limits discussed in the previous section we selected $\theta_{\text {eff }}<3.4^{\circ}\left(2.3^{\circ}\right.$ after 2004) for further calculations of the aspect sensitivity parameter.

Figure 2 shows one typical example of PMSE aspect sensitivity measurements during one day together with the radar backscattered power. It is evident from the figure that radar echoes are highly aspect sensitive (with $\theta_{\mathrm{s}}$ less than $2.2^{\circ}$ ) at the edges of PMSE layers, especially at the lower edges, and they are less aspect sensitive in the middle of the layers. The same features were observed during other days.

In order to study the variability of aspect sensitivity of PMSE from year to year we calculated distributions of aspect sensitivity parameter for each year. We used 1-min averaged data from all heights in the range $80-90 \mathrm{~km}$, for June and July. The results are shown in Fig. 3. The number of data points used for calculation of these distributions varies from year to year mainly because of changes in time allocation for the different radar observation modes while for the analysis we used the data only from the mode with a $150 \mathrm{~m}$ altitude resolution. The distributions are very similar, non-Gaussian in shape and have peak value at about $2.5^{\circ}$ and half maximum full width of $2^{\circ}-3^{\circ}$. The median values of $\theta_{\mathrm{s}}$ are in the range of $2.9^{\circ}-3.7^{\circ}$. This implies that PMSE are rather aspect sensitive. We calculated also the percentage of such echoes $\left(\theta_{\text {eff }}<3.4^{\circ}\right.$ or $2.3^{\circ}$ after 2004$)$ in the whole data set for each year. The results show that $50 \%-52 \%$ of data are represented by the distributions in Fig. 3, i.e. half of all PMSE observed with ESRAD are highly aspect sensitive. The other half of PMSE have aspect sensitivity parameter larger than $11^{\circ}\left(9^{\circ}\right.$ after 2004), i.e. scatter is more isotropic. However, we cannot calculate their exact values from the ESRAD data using the in-beam method as discussed in Sect. 3.

\subsection{Dependence of PMSE aspect sensitivity on altitude}

To check the dependence of PMSE aspect sensitivity on altitude, we computed the distribution of aspect sensitivity parameter $\theta_{\mathrm{s}}$ for each 150-m altitude range for every year. In Fig. 4 the results for 1998 for the initial antenna array configuration and for 2010 for the extended antenna array are presented. There each row represents an aspect sensitivity distribution function at certain height, with values (fraction of the data or occurrence frequency) depicted by colours. The pictures for these two years do not show big differences. We have verified the behaviour of the PMSE aspect sensitivity with height for the other years and found that it is similar to that for 1998 and 2010. The $\theta_{\mathrm{s}}$ altitude-frequency plot averaged over all of the 11 years is presented in Fig. 5. With increasing altitude the distribution becomes broader and the peak of the distribution moves to higher values of $\theta_{\mathrm{s}}$. Our calculations show that PMSE median aspect angle for seasons $1997-2010$ at $87-88 \mathrm{~km}$ altitude is $1-2^{\circ}$ larger than that at $81-82 \mathrm{~km}$. Thus we can conclude that PMSE are more isotropic at the higher altitudes.

\subsection{Dependence of PMSE aspect sensitivity on power}

We have investigated the dependence of PMSE aspect sensitivity on backscattered power for each PMSE season. We computed distributions of the aspect sensitivity parameter $\theta_{\mathrm{S}}$ as a function of the logarithm of the echo power for each 0.2 step. The results for 1998 and 2010 are presented in Fig. 6. Similar to Fig. 4, each row here represents an aspect sensitivity distribution function at certain value of PMSE backscattered power. Again we see that distributions for 1998 and 2010 are very similar and do not show obvious dependence of the PMSE aspect sensitivity on echo strength (for the high power there is an apparent decrease of aspect sensitivity, however this result is based on poor statistics - see the right panel). Figure 7 shows the distributions averaged over all of the 11 years, which reveals that PMSE aspect sensitivity is independent of echo backscattered power.

\section{Discussion}

As mentioned in the introduction the aspect sensitivity of PMSE has been measured using two methods: in-beam as in this paper and with tilted beams. Both methods suffer from limitations, some of them were considered by e.g. Hobbs et 

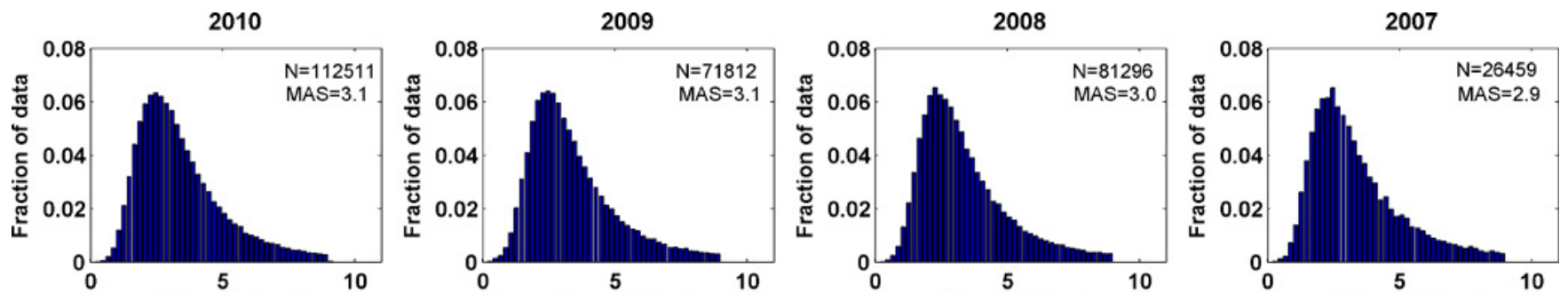

Aspect Sensitivity, degrees 2006

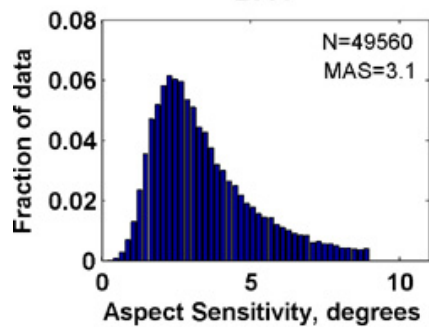

Aspect Sensitivity, degrees 2005

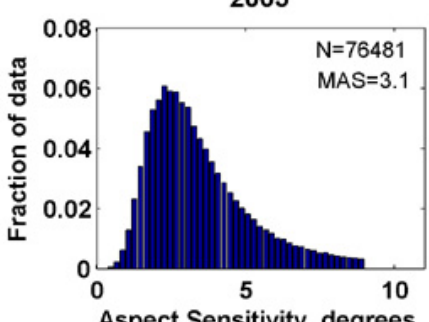

Aspect Sensitivity, degrees 2003

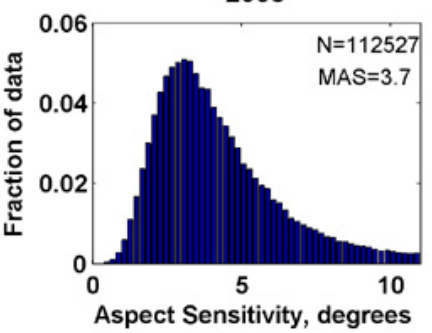

Aspect Sensitivity, degrees

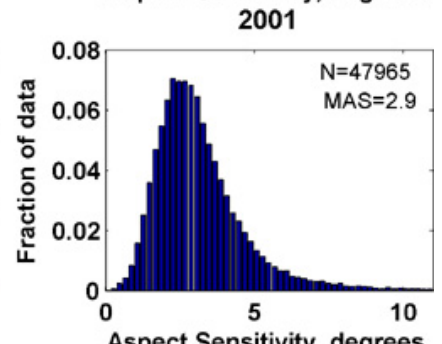
1998
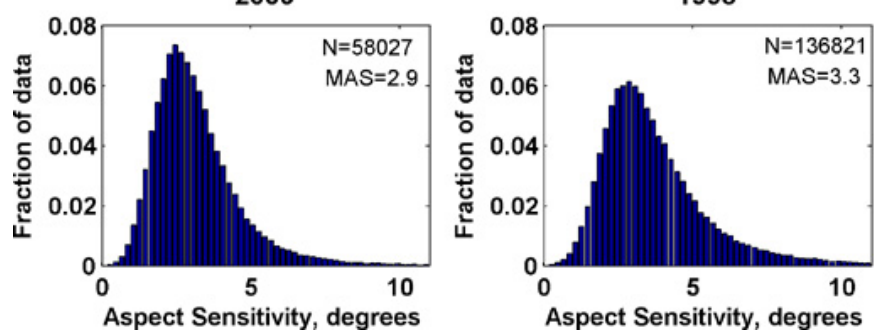
1997

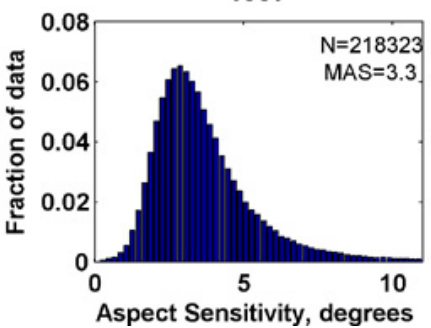

Fig. 3. The distributions of aspect sensitivity parameter for different years. $N$ is the total number of data points, MAS is the median aspect sensitivity parameter in degrees.
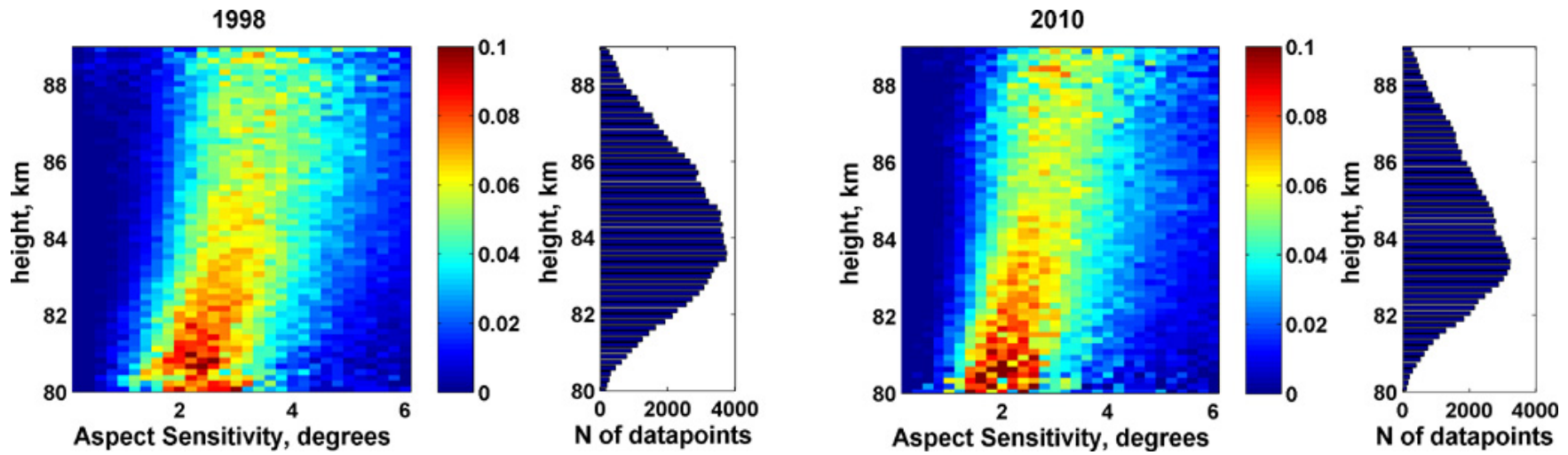

Fig. 4. The first and third panels: distribution of aspect sensitivity parameter for each 150-m altitude interval for 1998 and 2010 , respectively. Each row is normalized so that the sum of all data bins in it is 1 . The second and fourth panels: number $N$ of data points contributing to each altitude interval for 1998 and 2010, respectively.

al. (2001) and Chilson et al. (2002). Here we discuss limitations related to a finite radar beam-width only. In Sect. 3 we obtained the largest aspect angles $\theta_{\mathrm{S}}$ which are measurable with ESRAD using FCA. They are $9-11^{\circ}$ and determined by the two-way radar beam width. Thus using the ESRAD vertical beam we cannot measure the aspect sensitivity of more isotropic (turbulent) echoes. In contrast, for measure- ments using tilted beams the off-zenith angle should be at least one full radar beam-width (two-way) or larger in order that the sampling volumes for the vertical and tilted beams do not overlap each other. Hence the titled beam method is not suitable for quasi-specular echoes whose angular polar diagram width is less than the radar beam width (two-way) or the beam off-zenith angle. This implies that using one 


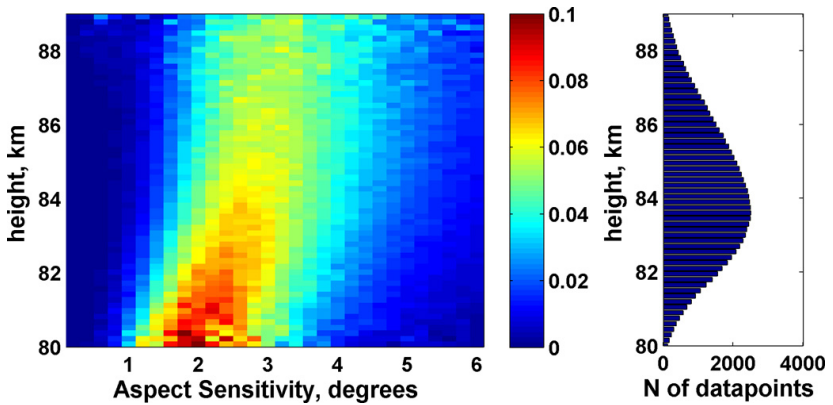

Fig. 5. Left panel: distribution of aspect sensitivity parameter for each 150-m altitude interval averaged over all 11 years. Each row is normalized so that the sum of all data bins in it is 1. Right panel: number $N$ of data points contributing to each altitude interval.

of two techniques we restrict ourselves to measurements of the part of the echoes produced by the certain type of scatterers. The values of aspect sensitivity parameter obtained with these two methods support our statement. Indeed, inbeam measurements of PMSE aspect sensitivity by Zecha et al. (2001) using FCA and Chilson et al. (2002) using CRI, resulted in typical values of $\theta_{\mathrm{s}}$ of $2-5^{\circ}$ and $2-3^{\circ}$, respectively. We obtained the most typical $\theta_{\mathrm{s}}$ to be in range from $1^{\circ}$ to $5^{\circ}$ which agrees well with those by Zecha et al. and Chilson et al. In turn, using the $8^{\circ}$ off-zenith beam, Zecha et al. (2001) obtained $\theta_{\mathrm{s}}$ in the range mostly $4-11^{\circ}$. Huaman and Balsley (1998) reported $\theta_{\mathrm{s}}$ of $12-13^{\circ}$ when a $15^{\circ}$ off-vertical beam was used. Most recently, Swarnalingam et al. (2011) found PMSE aspect angles of $8-13^{\circ}$ using titled beams at $10.9^{\circ}$ from zenith. The only result deviating from these values is an estimate that $\theta_{\mathrm{s}}$ ranged from $2-10^{\circ}$ reported by Czechowsky et al. (1988). A possible explanation is that they used beams tilted only $4^{\circ}$ and $5.6^{\circ}$ off-vertical and the radar had a very narrow full beam-width of $3^{\circ}$ (one-way). Thus we can conclude that the in-beam method allows detections of small aspect angles (just a few degrees) and correspondingly highly aspect sensitive echoes, whereas the method using offvertical radar beams, detects less aspect sensitive echoes.

On the basis of 11 years of observations we found that PMSE are more isotropic, less aspect sensitive at higher altitudes. A similar height dependence of PMSE aspect sensitivity has been reported in other studies (Czechowsky et al., 1988; Zecha et al., 2001; Chilson et al., 2002). Long-term aspect sensitivity measurements of PMSE at Resolute Bay by Swarnalingam et al. (2011) revealed that, for strong and moderate PMSE, the median aspect angles at $84 \mathrm{~km}$ are by $2-4^{\circ}$ smaller than those at $88 \mathrm{~km}$. Our results show slightly less difference of $1-2^{\circ}$ between aspect angles at $82 \mathrm{~km}$ and $87 \mathrm{~km}$. This morphology is supported by the results of rocket measurements of turbulence by Lübken et al. (2002). These show that turbulence occurrence rates start to grow from $80 \mathrm{~km}$ and maximise at about $88 \mathrm{~km}$ (Rapp and by Lübken, 2003).
Chilson et al. (2002) and Zecha et al. (2001) noticed the enhanced aspect sensitivity at the lower edges of PMSE sublayers. Similar features are seen in our Fig. 2. We do not address this topic here because it requires additional investigation whose results will be reported elsewhere.

Already the first measurements of PMSE aspect sensitivity by Czechowsky et al. (1988) showed its relation to echo power. The authors, based on two-day data, reported that the peaks in backscattered power profile correspond to minima in aspect angle profile. Similarly, Chilson et al. (2002) found for one-day data that PMSE regions with enhanced aspect sensitivity (small aspect angles) have high signal-to-noise ratio. However, Swarnalingam et al. (2011) analysed data for 11 years and did not find obvious correlation between PMSE aspect sensitivity and echo volume reflectivity. This result is in agreement with our findings. Swarnalingam et al. mentioned a possible tendency that strong PMSE have low aspect angles. Similar features can be seen in our Figs. 6 and 7. However, this apparent impression is based on poor statistics available for the strongest PMSE in our paper as well as in Swarnalingam et al. (2011).

We also found that the distribution of aspect sensitivity values, the median values for June-July and the dependences of value on altitude and power remain consistent over 11 years for the highly aspect sensitive PMSE over Esrange. Swarnalingam et al. (2011) reported for aspect sensitivity (with values in the range of $8-13^{\circ}$ derived using the DBS method) of PMSE over Resolute Bay that the long-term height dependences for moderate and strong echoes showed consistency during 1998-2009 as well.

Could the results we have obtained on aspect sensitivity of PMSE tell us about scattering mechanism and scatterers? In some studies (e.g. Hoppe et al., 1990; Blix et al., 1999) there were attempts to relate echo power, spectral width and aspect sensitivity in order to identify turbulent scattering or specular reflection. We did not analyse PMSE spectral widths in this paper, so we have to restrict ourselves to aspect sensitivity only. It is commonly accepted that PMSE are related to neutral turbulence (e.g. Rapp and Lübken, 2004). Intensive modelling studies of turbulence generated at mesopause altitudes showed anisotropy of the turbulence fields and radar backscatter (Gibson-Wilde et al., 2000; Fritts et al., 2003, 2009 , 2011). However, to our knowledge there is no quantitative estimation of aspect sensitivity for such turbulence so far (perhaps with the exception of Hocking and Hamza (1997) who analytically considered anisotropic turbulence due to wind-shear only). Anyway, small values of half-width of the scatterers' polar diagram (about $3^{\circ}$ ) obtained in this study allow us to exclude isotropic turbulent scatter at least for $50 \%$ of PMSE detected with ESRAD. However, additional measurements and perhaps, numerical simulations are needed to make any decisive conclusion whether the observed PMSE aspect sensitivities are due to anisotropic turbulent or Fresnel scatter. 


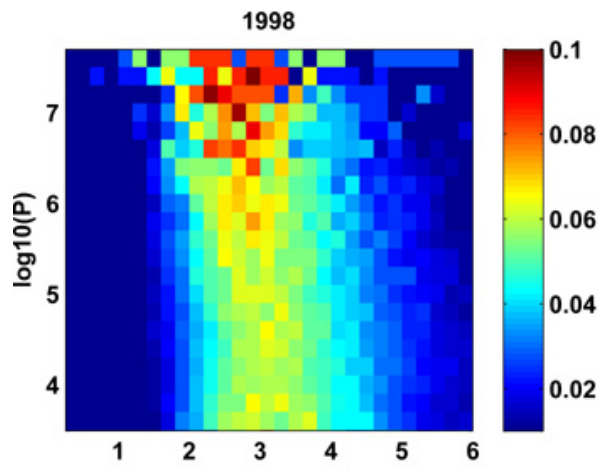

Aspect Sensitivity, degrees

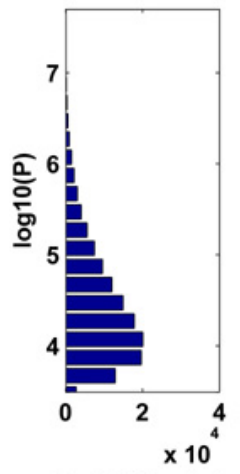

$\mathrm{N}$ of datapoints
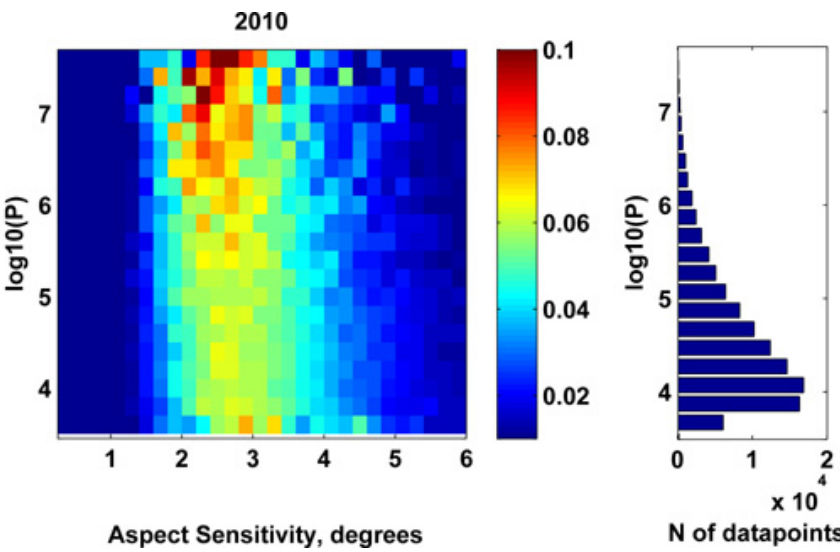

$\mathrm{N}$ of datapoints

Fig. 6. The first and third panels: distribution of PMSE aspect sensitivity parameter for 1998 and 2010, respectively. Each row is normalized so that the sum of all data bins in it is 1 . The second and fourth panels: number $N$ of data points contributing to each row for 1998 and 2010 , respectively.

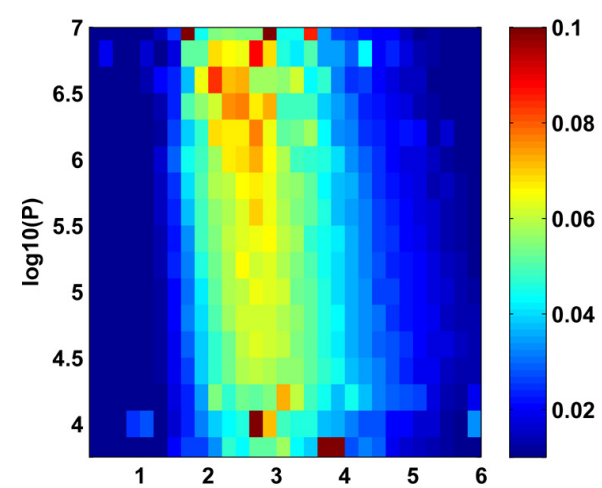

Aspect Sensitivity, degrees

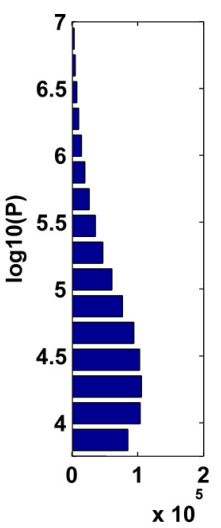

$\mathrm{N}$ of datapoints

Fig. 7. Left panel: distribution of PMSE aspect sensitivity parameter for each interval of echo power averaged over all 11 years. Each row is normalized so that the sum of all data bins in it is 1 . Right panel: number $N$ of data points contributing to each row.

We found that half of all PMSE detected by ESRAD have high aspect sensitivity. If PMSE are strongly aspect sensitive this can affect estimation of their absolute strength expressed in terms of volume reflectivity $\eta$. In the calculation of $\eta$ it is assumed that scatter is isotropic and fills the entire radar sampling volume. However, if the scatterers' polar diagram is narrower than that of the two-way radar beam then one underestimates their volume reflectivity. We evaluate this effect for ESRAD using our results on PMSE aspect sensitivity.

Volume reflectivity $\eta$ is defined as a total power scattered isotropically by unit scatterers' volume, per unit transmit power, per unit solid angle. Consequently, for a given measured echo power, for narrow and moderate beam radars $\eta$ is inversely proportional to the effective radar volume $V_{0}$, which is approximated as follows (Hocking, 1985)

$V_{0} \approx \pi\left(h \theta_{\mathrm{TR}}\right)^{2} \Delta h$,

where $\theta_{\mathrm{TR}}$ is the $\mathrm{e}^{-1}$ half-width of the two-way radar polar diagram, $h$ is altitude, $\Delta h$ is altitude resolution. For aspect sensitive scatter the effective radar volume is determined by $\theta_{\text {eff. }}$. We have calculated $\theta_{\text {TR }}$ to be $3.6^{\circ}$ before the ESRAD antenna extension in 2004, and $2.4^{\circ}$ afterward, and median values of $\theta_{\mathrm{s}}$, averaged over the first and the second intervals are $3.2^{\circ}$ and $3.1^{\circ}$, respectively. By using Eq. (4) we came to the values of $\theta_{\text {eff }}$ of $2.4^{\circ}$ and $1.9^{\circ}$ before and after 2004, respectively. Finally, we found that we underestimated volume reflectivity of at least half of PMSE (those which are aspect sensitive) detected with ESRAD by factor of 1.6-2.3 (by 2-3.5 dB). For comparison, Swarnalingam et al. (2009a) reported $0.3 \mathrm{~dB}$ possible effect due to high aspect sensitivity $\left(5^{\circ}\right)$ evaluated for the Resolute Bay VHF radar with $1.4^{\circ}$ two-way radar beam width.

\section{Summary}

We used ESRAD PMSE data for 1997-2010 for calculation of in-beam PMSE aspect sensitivities for 11 years using the FCA technique. We found that $50-52 \%$ of data can be identified as highly aspect sensitive echoes. The rest of PMSE have aspect sensitivity parameters $\theta_{\mathrm{s}}$, characterising the halfwidth of the scatterers' polar diagram, larger than $9-11^{\circ}$ and their values cannot be quantified using the ESRAD vertical beam measurements only.

We calculated the distribution of PMSE over aspect sensitivity parameter $\theta_{\mathrm{s}}$ for each year and found that they remain consistent from year to year. The median values of $\theta_{\mathrm{S}}$ are in $2.9-3.7^{\circ}$ range. It was found that when calculating volume reflectivity for such aspect sensitive PMSE, one can underestimate it by more than $3 \mathrm{~dB}$.

We found also that $\theta_{\mathrm{s}}$ slightly increases with altitude (by $1-2^{\circ}$ from $82 \mathrm{~km}$ to $87 \mathrm{~km}$ ). This altitude dependence of $\theta_{\mathrm{S}}$ 
does not change from year to year. No dependence of PMSE aspect sensitivity on backscattered power for any year was identified.

We analysed the limitations of the in-beam and off-zenith beam methods related to the finite radar beam width. Our conclusion is that the former is suitable for highly aspect sensitive echoes while the latter is needed for more isotropic scatterers. Both techniques should be combined in order to get full information about PMSE aspect sensitivity.

Acknowledgements. ESRAD radar is a joint venture between Swedish Space Corporation, Esrange and Swedish Institute of Space Physics. The work of Maria Smirnova was funded by The Swedish National Graduate School of Space Technology hosted by Luleå University of Technology. This work has otherwise been funded by the Swedish Research Council grant 621-2007-4812.

Topical Editor C. Jacobi thanks two anonymous referees for their help in evaluating this paper.

\section{References}

Blix, T. A.: Small scale plasma and charged aerosol variations and their importance for polar mesosphere summer echoes, Adv. Space Res., 24, 537-546, 1999.

Briggs, B. H.: The analysis of spaced sensor records by correlation techniques, MAP Handbook, 13, 166-168, 1985.

Chen, J.-S., Hoffmann, P., Zecha, M., and Röttger, J.: On the relationship between aspect sensitivity, wave activity, andmultiple scattering centers of mesosphere summer echoes: a case study using coherent radar imaging, Ann. Geophys., 22, 807817, doi:10.5194/angeo-22-807-2004, 2004.

Chilson, P. B., Kirkwood, S., and Nilsson, A.: The Esrange MST radar: A brief introduction and procedure for range validation using balloons, Radio Sci., 34, 427-436, 1999.

Chilson, P. B., Yu, T.-Y., Palmer, R. D., and Kirkwood, S.: Aspect sensitivity measurements of polar mesosphere summer echoes using coherent radar imaging, Ann. Geophys., 20, 213-223, doi:10.5194/angeo-20-213-2002, 2002.

Czechowsky, P., Reid, I. M., and Rüster, R.: VHF radar measurements of the aspect sensitivity of the summer polar mesopause over Andenes $\left(69^{\circ} \mathrm{N}, 16^{\circ} \mathrm{E}\right)$ Norway, Geophys. Res. Lett., 15, 1259-1262, 1988.

Fritts, D. C., Bizon, C., Werne, J. A., and Meyer, C. K.: Layering accompanying turbulence generation due to shear instability and gravity-wave breaking, J. Geophys. Res., 108, 8452, doi:10.1029/2002JD002406, 2003.

Fritts, D. C., Wang, L., Werne, J., Lund, T., and Wan, K.: Gravity Wave Instability Dynamics at High Reynolds Numbers. Part II: Turbulence Evolution, Structure, and Anisotropy, J. Atmos. Sci., 66, 1149-1171, doi:10.1175/2008JAS2727.1, 2009.

Fritts, D. C., Franke, P. M., Wan, K., Lund, T., and Werne, J.: Computation of clear-air radar backscatter from numerical simulations of turbulence: 2 . Backscatter moments throughout the lifecycle of a Kelvin-Helmholtz instability, J. Geophys. Res., 116, D11105, doi:10.1029/2010JD014618, 2011.

Gibson-Wilde, D. E., Werne, J. A., Fritts, D. C., and Hill, R. J.: Direct numerical simulation of VHF radar measurements of turbulence in the mesosphere, Radio Sci., 35, 783-798, 2000.
Hobbs, B. G., Reid, I. M., and Holdsworth, D. A.: A comparison of tropospheric VHF Doppler beam steering and full correlation analysis measurements of aspect sensitivity, Radio Sci., 36, 955964, doi:10.1029/2000RS002360, 2001.

Hocking, W. K.: Measurement of turbulent energy dissipation rates in the middle atmosphere by radar techniques: a review, Radio Sci., 20, 1403-1422, 1985.

Hocking, W. K. and Hamza, A. M.: A quantitative measure of the degree of anisotropy of turbulence in terms of atmospheric parameters, with particular relevance to radar studies, J. Atmos. Sol. Terr. Phys., 59, 1011-1020, 1997.

Hocking, W. K., Rüster, R., and Czechowsky, P.: Absolute reflectivities and aspect sensitivities of VHF radio wave scatterers measured with the SOUSY radar, J. Atmos. Terr. Phys., 48, 131-144, 1986.

Holdsworth, D. A.: Signal analysis with applications to atmospheric radars, Ph.D. thesis, University of Adelaide, 1995.

Hoppe, U.-P., Fritts, D. C., Reid, I. M., Czechowsky, P., Hall, C., and Hansen, T. L.: Multiple-frequency studies of the highlatitude summer mesosphere: Implication for scattering processes, J. Atmos. Terr. Phys., 52, 907-926, 1990.

Huaman, M. M. and Balsley, B. B.: Long-term-mean aspect sensitivity of PMSE determined from Poker Flat MST radar data, Geophys. Res. Lett., 25, 947-950, 1998.

Kirkwood, S., Wolf, I., Nilsson, H., Dalin, P., Mikhaylova, D., and Belova, E.: Polar mesosphere summer echoes at Wasa, Antarctica $\left(73^{\circ} \mathrm{S}\right)$ : First observations and comparison with $68^{\circ} \mathrm{N}$, Geophys. Res. Lett., 34, L15803, doi:10.1029/2007GL030516, 2007.

Kirkwood, S., Belova, E., Satheesan, K., Narayana Rao, T., Rajendra Prasad, T., and Satheesh Kumar, S.: Fresnel scatter revisited - comparison of $50 \mathrm{MHz}$ radar and radiosondes in the Arctic, the Tropics and Antarctica, Ann. Geophys., 28, 1993-2005, doi:10.5194/angeo-28-1993-2010, 2010.

Latteck, R., Singer, W., Morris, R. J., Hocking, W. K., Murphy, D. J., Holdsworth, D. A., and Swarnalingam, N.: Similarities and differences in polar mesosphere summer echoes observed in the Arctic and Antarctica, Ann. Geophys., 26, 2795-2806, doi:10.5194/angeo-26-2795-2008, 2008.

Lübken F.-J., Rapp, M., and Hoffmann, P.: Neutral air turbulence and temperatures in the vicinity of polar mesosphere summer echoes, J. Geophys. Res., 107, 4273, doi:10.1029/2001JD000915, 2002.

Morris, R. J., Klekociuk, A. R., Latteck, R., Singer, W., Holdsworth, D. A., and Murphy, D. J.: Inter-hemispheric asymmetry in polar mesosphere summer echoes and temperature at $69^{\circ}$ latitude, J. Atmos. Sol. Terr. Phys., 71, 464-469, 2009.

Rapp, M. and Lübken, F.-J.: On the nature of PMSE: Electron diffusion in the vicinity of charged particles revisited, J. Geophys. Res., 108, 8437, doi:10.1029/2002JD002857, 2003.

Rapp, M. and Lübken, F.-J.: Polar mesosphere summer echoes (PMSE): Review of observations and current understanding, Atmos. Chem. Phys., 4, 2601-2633, doi:10.5194/acp-4-2601-2004, 2004.

Swarnalingam, N., Hocking, W. K., and Argall, P. S.: Radar efficiency and the calculation of decade-long PMSE backscatter cross-section for the Resolute Bay VHF radar, Ann. Geophys., 27, 1643-1656, doi:10.5194/angeo-27-1643-2009, 2009a.

Swarnalingam, N., Hocking, W. K., Singer, W., and Latteck, R.: Calibrated measurements of PMSE strengths at three different 
locations observed with SKiYMET radars and narrow beam VHF radars, J. Atmos. Sol. Terr. Phys., 71, 1807-1813, 2009b.

Swarnalingam, N., Hocking, W. K., and Drummond, J. R.: Longterm aspect-sensitivity measurements of polar mesosphere summer echoes (PMSE) at Resolute Bay using a $51.5 \mathrm{MHz}$ VHF radar, J. Atmos. Sol. Terr. Phys., 73, 957-964, 2011.
Thomas, G. E. and Olivero, J.: Noctilucent clouds as possible indicators of global change in the mesosphere, Adv. Space Res., 28, 937-946, 2001.

Zecha, M., Röttger, J., Singer, W., Hoffmann, P., and Keuer, D. Scattering properties of PMSE irregularities and refinement of velocity estimates, J. Atmos. Sol. Terr. Phys., 63, 201-214, 2001. 